Original Research Paper

\title{
Development of a Mechatronic Control System for a Mechanical Fuel Injection System of a Four Cylinder Automotive Diesel Engine By using Matlab and Simulink
}

\author{
${ }^{1}$ Mostafa Abdulrahman Kortam, ${ }^{1}$ Farid Abdulaziz Tolba and ${ }^{2}$ Adham Mohamed Abdelkader Hassen \\ ${ }^{I}$ Faculty of Engineering, Mechatronics Engineering Department, Ainshams University, Cairo, Egypt \\ ${ }^{2}$ Faculty of Engineering, Automotive Engineering Department, Ainshams University, Cairo, Egypt
}

\author{
Article history \\ Received: 03-02-2018 \\ Revised: 07-03-2018 \\ Accepted: 22-03-2018 \\ Corresponding Author: \\ Mostafa Abdulrahman Kortam \\ Faculty of Engineering, \\ Mechatronics Engineering \\ Department, Ainshams \\ University, Cairo, Egypt \\ Email: mostafakortam@hotmail.com
}

\begin{abstract}
The aim of this paper is to develope a mechatronic control system to replace mechanical fuel injection system of a four-cylinder automotive diesel engine, to study what are the important electronics fuel injection parameters which have the highest effect on the engine performance. All the paperwork performed on Isuzu engine 4HF1 which is 4 cylinder diesel engine working with fully mechanical fuel injection system. To develop mechatronics fuel system, must install crank sensor which measure the engine speed in RPM and specify the piston position, cam sensor which specifies the injection order, common rail fuel injection system which includes electronic injectors, high pressure pump and common rail, ECU which control all the system inputs and outputs and injectors driver controller which responsible for delivering the required high voltage for the injectors with high speed switching. ECU software will be developed from scratch to develop injection quantity, injection time and injection order output signals to be compatible with the common rail fuel system. Mathworks tools (Matlab-Simulink-Stateflow) will be used for developing ECU software application layer which divided into many models as crankshaft speed model, crankshaft sensor piston position, cam sensor injection order model, pedal speed model, injectors model, torque model and final model which collect all the previous models. Embedded coder toolbox will be used for generating $\mathrm{C}$ code which will be integrated with the microcontroller layer and uploaded to the selected ECU.
\end{abstract}

Keywords: Diesel Engine, Internal Combustion Engine, Engine Management System, Diesel Engine Software, Engine Modeling and Simultaion, Engine Embedded System

\section{Introduction}

The Internal combustion engine industry is one of the fastest growing industries in the world since it is the heart of a lot of applications as automotive industries, heavy equipment, power generation and a lot of other applications, so there is a big need to enhance the performance for internal combustion engine continuously.

Engines manufacturer expenses a lot of money on research and development trying to figure out a lot of new enhancements of many parameters as, decreasing fuel consumption, sounds, vibration, emissions and increaseing power and torque.
Mechatronics now plays an important role in these enhancements, so most of the internal combustion engines now contains a lot electronics and controllers so in this paper a mechatronic control system will be developed to replace mechanical fuel injection system of a four-cylinder automotive diesel engine, to study what are the important electronics fuel injection parameters which have the highest effect on the engine performance.

\section{Cam Sesnor SND Reluctor Wheel Installation}

Due to overhead cam tight area which does not allow the installation of a reluctor wheel, four small separate teeth have been machined and stuck onto the camshaft 
gear, one of these teeth is wider than others, so as to be marked tooth, with tooth thickness being $0.5 \mathrm{~cm}$, tooth width being $0.9 \mathrm{~cm}$ and the wider tooth width being 2.7 $\mathrm{cm}$. since the space between the camshaft gear and the rocker arm end is $0.41 \mathrm{~cm}$, there is not enough space for the tooth to rotate freely without hitting the rocker arm. So, for free rotation the rocker arm has been grinded down to $0.15 \mathrm{~cm}$ (Fig. 1)

\section{Cam Reluctor Wheel Teeth Installation}

For teeth installation, crankshaft rotated until piston one has been at TDC in combustion position 3rd stroke then the first tooth which is the wider tooth stuck onto the cam gear directly under the cam sensor surface area (Fig. 2), the second tooth installed after first tooth by 90 degrees, after other 90 degrees the third and finally the fourth tooth so, when the cam sensor detecting the wider tooth this means that the piston 1 in the position of fuel injection.

\section{Cam Sensor Installation}

\section{Testing the Cam Sensor and Tooths Signal}

The overhead engine cover drilled with diameter 1.33 $\mathrm{cm}$ to fit the sensor (Fig. 3).
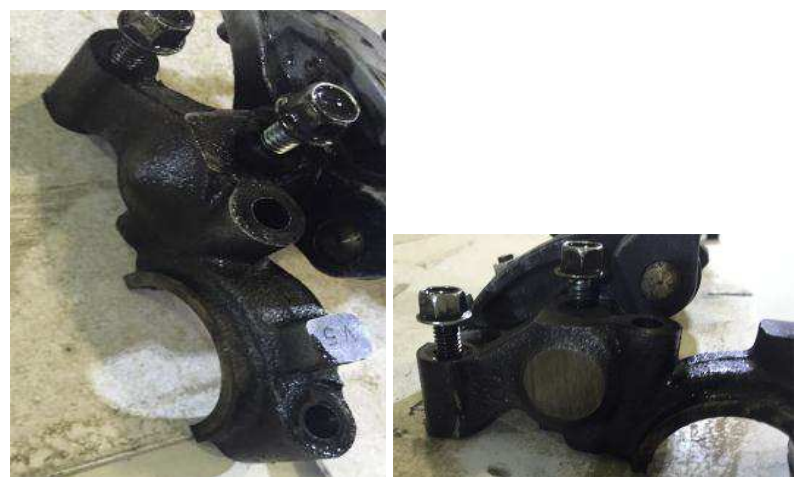

Fig. 1: Rocker arm before and after grinding

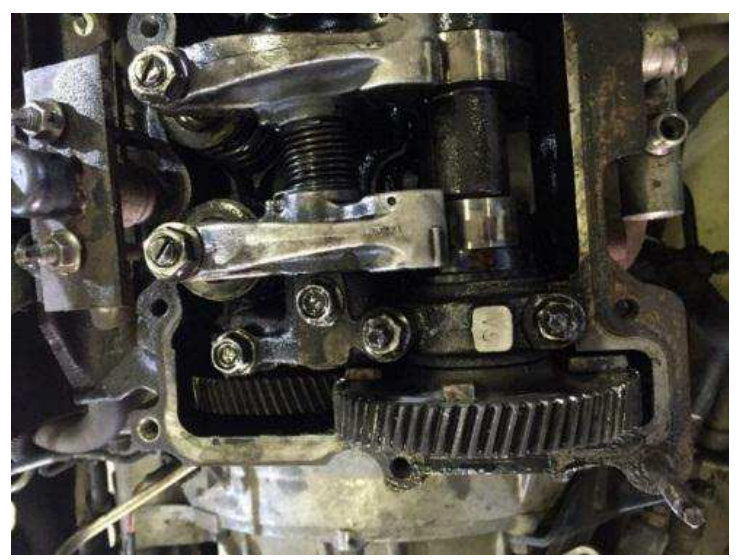

Fig. 2: Cam sensor tooths installation

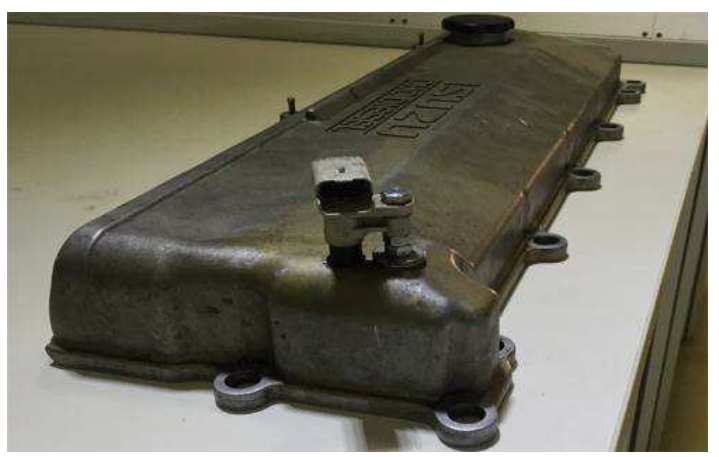

Fig. 3: Cam sensor installation

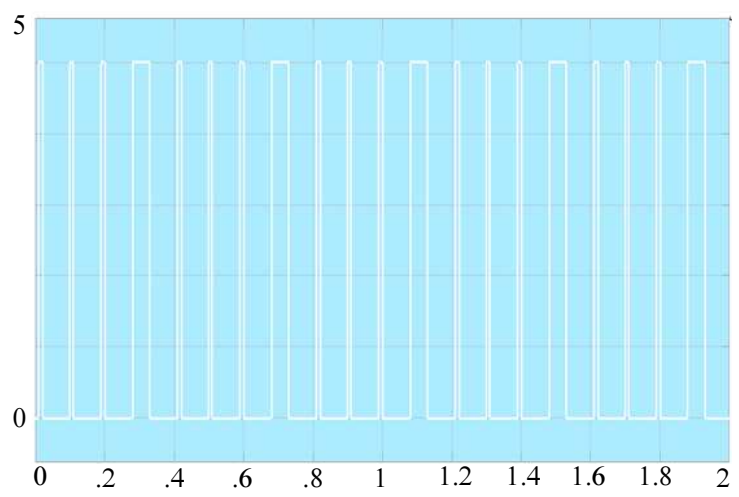

Fig. 4: Cam sensor signal detected by oscilloscope

Figure 4 show for repeated pulses three with a small width and the fourth pulse with a wider width which clears the sensor detection of the four tooths.

\section{Crank Sesnor and Reluctor Wheel Installation}

There is a special hole already exists at the flywheel housing with diameter $1.75 \mathrm{~cm}$ fitted for the crank sensor, a special reluctor ring machined to be fitted over the flywheel and directly under the hole with diameter 42 and 59 tooths.

\section{Reluctor Wheel Installation over the Flywheel}

Since the isuzu 4HF1 manufacturer mark the crankshaft pully with marks which specify piston position in degrees before TDC, so for reluctor wheel installation, the crankshaft turned until the timming mark on the crankshaft damper is alighned with the BTDC mark which is 12 degrees before TDC (Fig. 5) then the reluctor wheel installed (Fig. 6) with consideration the missing tooth will be under the sensor surface area directly, this means, when detecting marked tooth the piston will be before the TDC by 12 degrees.

\section{Crank Sensor Installation}

\section{Testing Crank Sensor by Oscilloscope}

There is a manufacturer made hole with $1.75 \mathrm{~cm}$ diameter at the gearbox casing which can fit the crank sensor and will be directly over the reluctor ring (Fig. 7). 


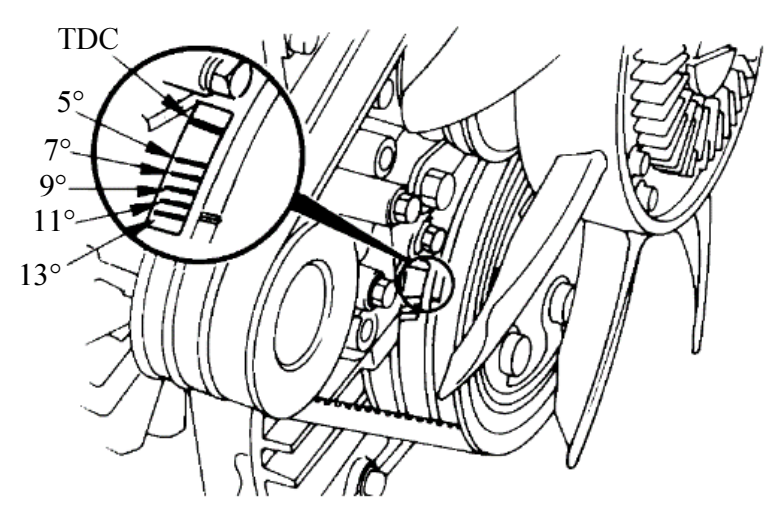

Fig. 5: ISUZU piston position in degrees

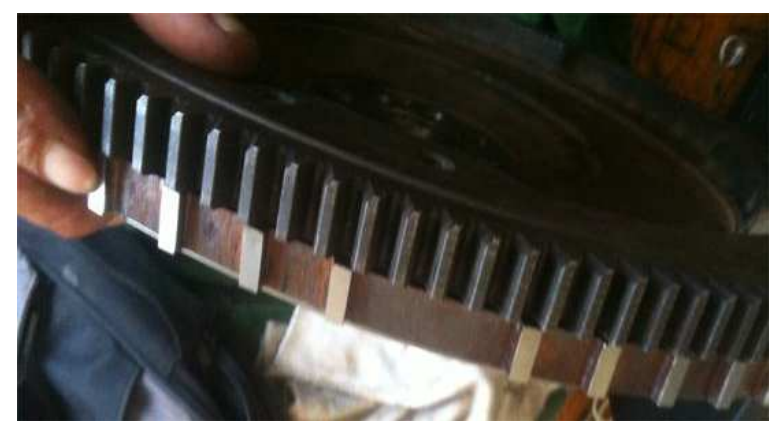

Fig. 6: The missing tooth

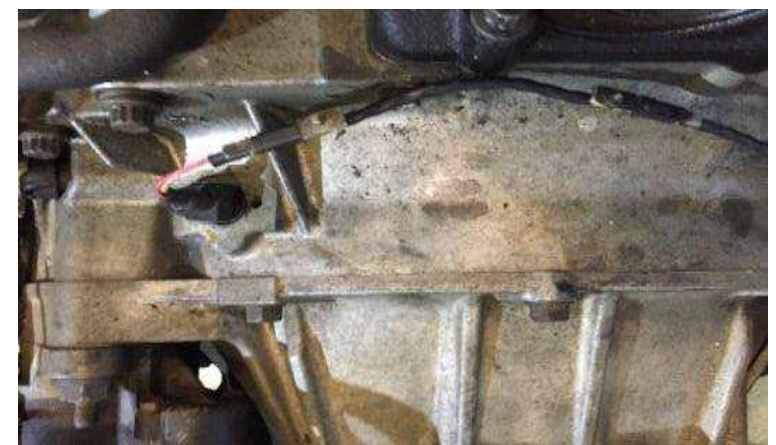

Fig. 7: Crank sensor installation

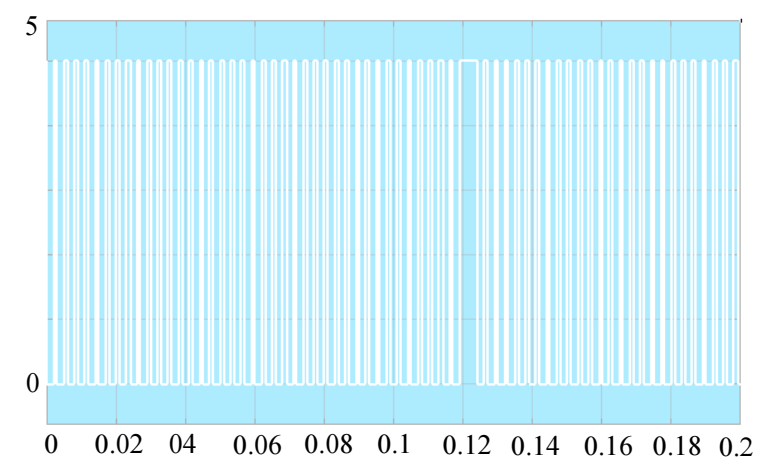

Fig. 8: Crank sensor signal detected by oscilloscope
Figure 8 show for repeated pulses with a small width and one different pulse with a wider width which clears the sensor detection of the tooths and the wider tooth.

\section{Installing the Electrical Injectors}

\section{Selected Injector}

Siemens common rail electronic injector with part number 9636819380 the main reason for selecting this injector, it has same geometry of the Isuzu injector and same diameter, so there is no need to make any modification on the engine cylinder head, but there are other differences as follows:

1. There is a small difference in dimension at the middle of the injector but it solved by made a little grinding at the middle of the injector body

2. The injector body does not have the compression seal as in the Isuzu injector so it grinded for seal installation (Fig. 9)

3. The Siemens injector comes with ignored nozzle hole angle data so it replaced with Denso nozzle (NDDLLA 154P717) which has same Isuzu injector nozzle specs $5 \times 0.215 \times 154$ and same nozzle diameter, but there is a difference in nozzle length (Fig. 10). Length problem solved by made a special ring seat, installed under the injector seat and since the Siemens injector nozzle length $2.25 \mathrm{~cm}$ and Isuzu injector nozzle $2.13 \mathrm{~cm}$ the ring thickness is the difference $=0.12 \mathrm{~cm}$ and machined to has the same geometry as original injector nozzle seats as (Fig. 11)

4. The Isuzu injector tighten socket could not be used with the common rail injector due to the geometry of the electronic solenoid and this problem solved by made a special new one (Fig. 12), (Fig. 13)

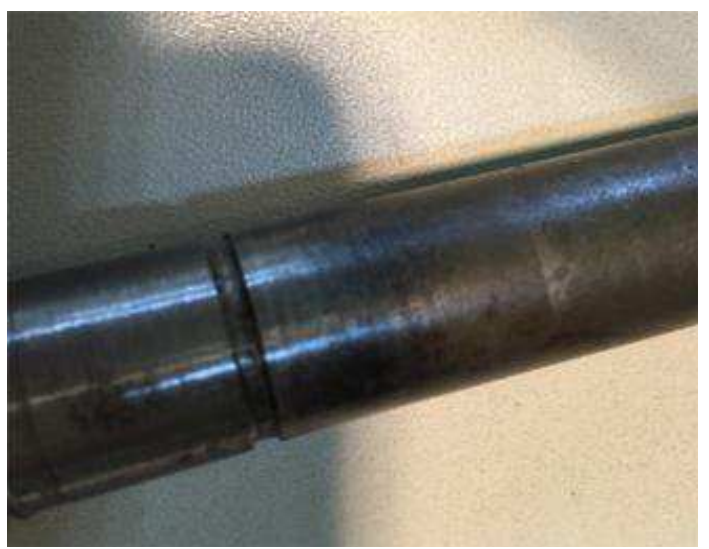

Fig. 9: Injector after grinding and making seal groove 


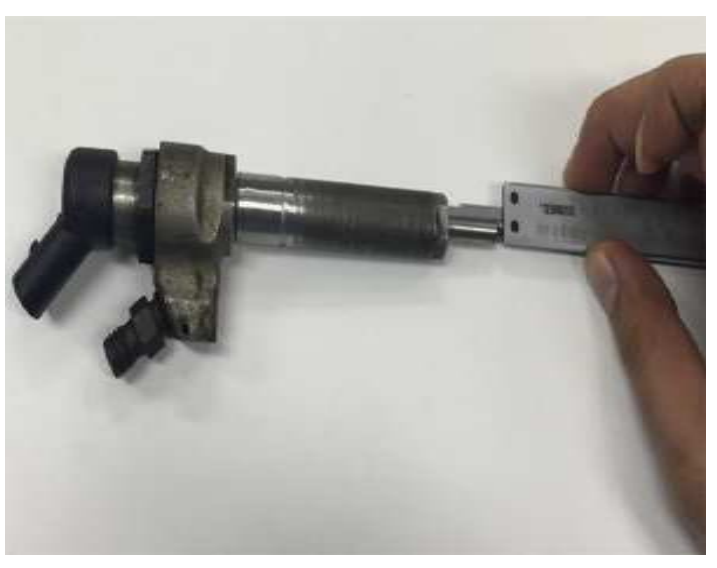

Fig. 10: Measureing Siemens injector nozzle length

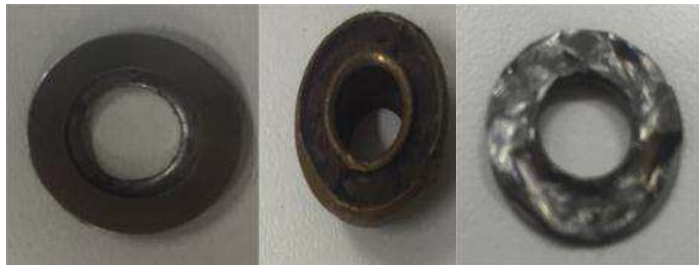

Fig. 11: Machining of the seat ring upper face to fit with the old seat

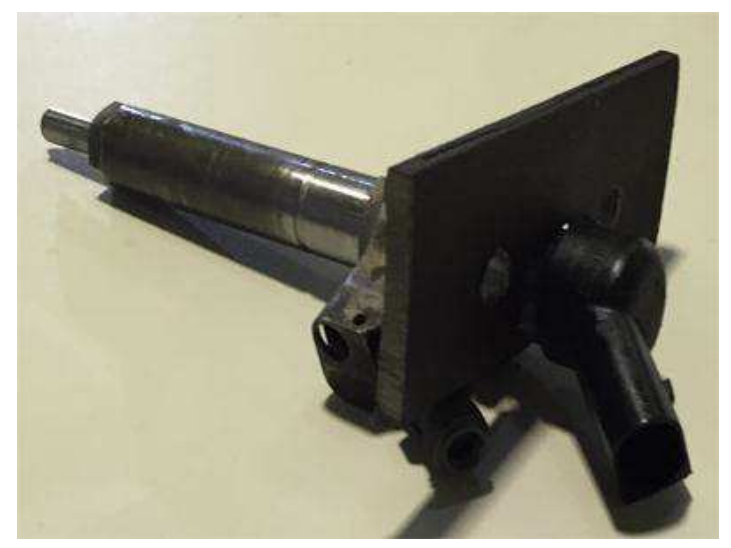

Fig. 12: Injector tighten socket

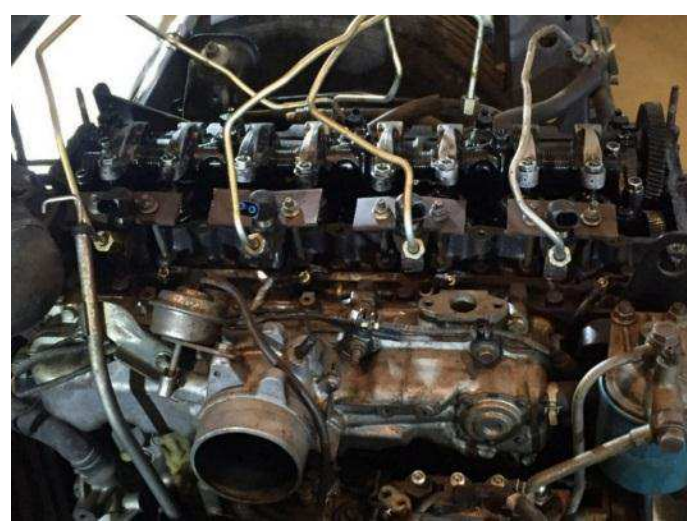

Fig. 13: After installing the injectors

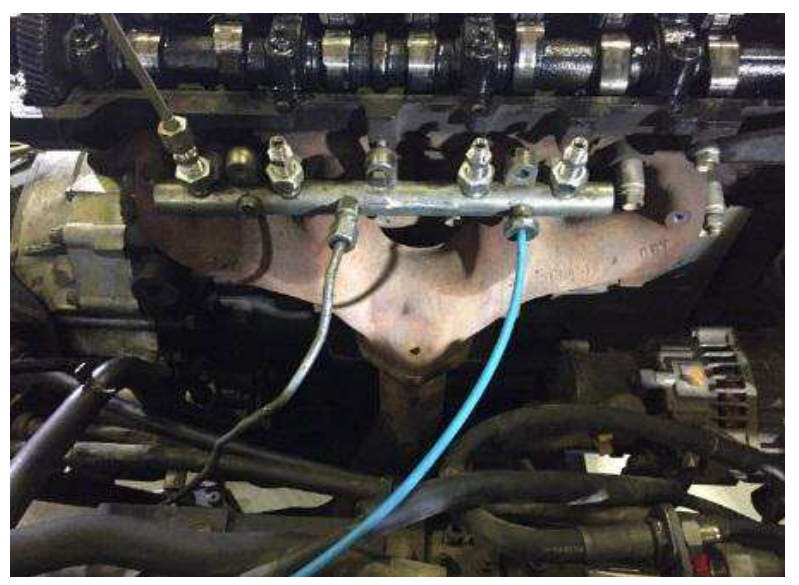

Fig. 14: Installing common rail with inlet and return pipes

\section{Common Rail Pupm and Rail Installation}

It is a high-pressure pump (1600 bar), only responsible for injecting a high pressure fuel in the common rail, so it does not control anything or have any effect on engine injection timing which allow to replace it is external gear with any one suitable with the engine, but the main problem is the pump geometry and dimensions, since the area which the Isuzu inline pump is installed is not big enough, this problem solved by removing the power steering pump and using it is place for the common rail pump.

The rail has been installed upper the pump since there a fixation area available already by Isuzu manufacturer made (Fig. 14).

\section{Engine Controllers}

Ecu

Engine manufacturers usually use expensive high quality processor to guarantee high processing speed and zero errors since it working with hard real time software, according to the project low-cost, raspberry pi with the following specs will be a suitable choice: Raspberry Pi 3 Model B a quad-core 64-bit ARM-Cortex A53 clocked at a $1.2 \mathrm{GHz}$.

\section{Injectors Driver Controller}

This controller responsible for transferring the signal from the ECU to the injectors in high-speed switching with write voltage.

Injectors driver controller circuit includes:

1. DC-DC Boost Converter $8-32 \mathrm{~V}$ to $45-390 \mathrm{~V}$ since the common rail injectors is a piezoelectric type with $100 \mathrm{v}$

2. TIP31C transistor used for high speed switching with high dc voltage due to injector high voltage at $100 \mathrm{v} d c$ 


\section{Ecu Software}

Typical powertrain control strategies contain several hundred thousand lines of $\mathrm{C}$ code and thousands of associated parameters and calibration variables requiring thousands of man-hours to calibrate, although the ongoing efforts in self-calibrating approaches and tools may substantially reduce this time-consuming task. Mathworks tools play important role in design the embedded system algorithms for Automotive industry. Using Mathworks products, Simulink, Stateflow and Embedded coder allow generating $\mathrm{C}$ code which can be ported to the microcontroller (Schäuffele and Zurawka, 2005), (Hoag and Dondlinger, 2006).

The AUTOSAR architecture (AUTOSAR, 2017). Layered software architecture part of realease 4.3.1) distinguishes on the highest abstraction level between three software layers:

Application, Runtime Environment and Basic Software which run on a Microcontroller.

Mathworks tool (Matlab, Simulink, Statesflow and Embedded Coder) will be used to develop the application layer as follows:

1. Crank sensor speed model

2. Crank sensor piston position model

3. Cam sensor injection order model

4. Pedal speed sensor model

5. Injectors model

6. Torque model

7. Final model

Before starting software developing there is an important note must be taken into consideration through software developing, changing the injection frequency will decrease or increase the engine rpm but changing the fuel injection quantity will decrease or increase the engine load.

\section{Crank Shaft Sensor Speed Model}

This model measure the engine speed (RPM), it will count every high pulse detected by the crank sensor and since the reluctor wheel is 59 tooths, when sensor detects 59 high signal, this will be one rpm, Simulink model blocks (Fig. 15) (Bonnick, 2001; Zurawski, 2009):

1. Model starting with comparing block to compare the pulse high or low

2. The results of comparing will be input to if condition block, if it 1 means signal is high and will store 1 in data store $A$, if 0 means signal is 0 and will store 2 in the data store B

3. Comparing data store B with 2 , if correct then the output will be 1 and if false the output will be 0

4. Comparing the result of comparing data store B and data store A with AND logic block, if the result is 1 this means the pulse is high
5. The output of AND logic block will be input to switch block, if the input is one then the output will be 1 going to the counting cycle which will start to count 1, this means the first detection of a high signal, in same time the data store block A and B will be reset to be zero value

6. In case the output of the switch block is 0 then there is no any added value to counter, in same time the values of data store block $A$ and $b$ will be same values, for example when model started and if block detect one then the data store A block will be 1 and no any add to store B, if data store B still contains zero due to reset with 0 , the output of AND 10 will be 0 , means no detection for high pulse and the values of data stores blocks will be same, this because the signal may be high but also it is may give 1 at start of high or middle or end or through any point on the pulse width, so this value will not be detected as high until detection of zero occur, in this case the data store B will be 2 and AND logic block will give 1 and the signal will be detected as high

\section{Crank Sensor Piston Position Model and Cam Injection Order Model}

This model will compare every tooth width with the next one until detecting the wider one, the model has five subsystems blocks (first tooth subsystem blocknext tooth- model reseting-comparing-independent subsystem block) Starting with crank speed model, after detecting the high pulse the output of the AND logic block will be input to the $\mathrm{K}$ data store block and the independent subsystem Block which contains the following blocks (Fig. 16):

1. F data store connected to increment stored integer block with initial value 0

2. J data store connected to decrement stored integer block with initial value 4

3. Enable block, every time this subsystem receiving 1 it will decrease the data store $\mathrm{J}$ and increase the data store F block by 1 Model reseting subsystem

It used to reset $\mathrm{F}$ and $\mathrm{J}$ data store blocks:

1. The data store $F$ block starting initially with 0 then increased to 1 then 2 and reset to 0 value when it reaches 2

2. The J block will starting initially with 4 then decreased to 3 then 2 then 1 and reset to 4 when it is value reaches 0

The first tooth subsystem.

It is enabled subsystem contain counter which start counting when enable block receiving 1 from the main input signal, the result of this counter will be input to switch block and will be added to the $\mathrm{C}$ data store block in case the value of data store $F$ is 1 , if not equal 1 it will keep the same previous value of data store $\mathrm{C}$ as it is. 


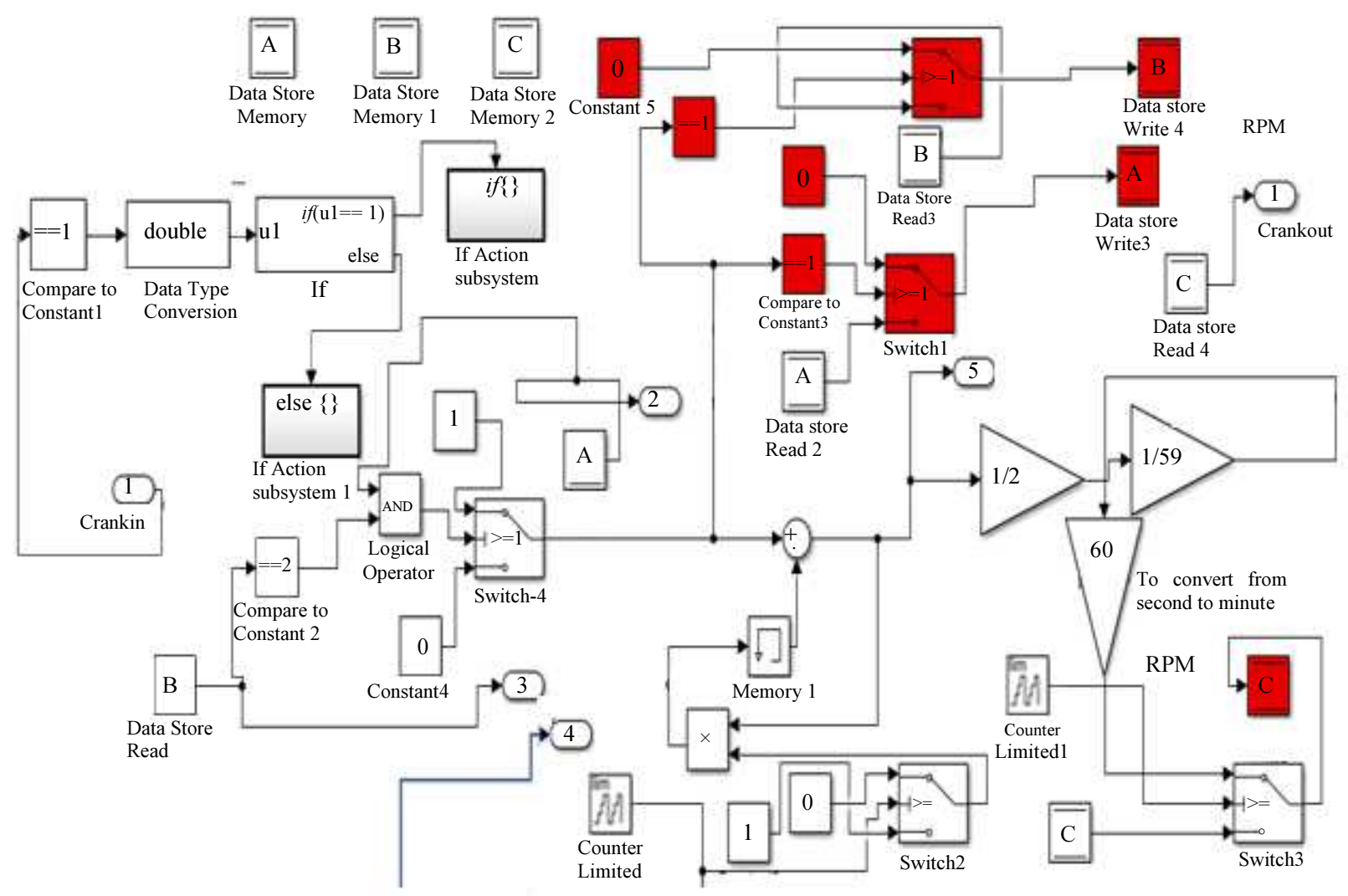

Fig. 15: Crank sensor speed model

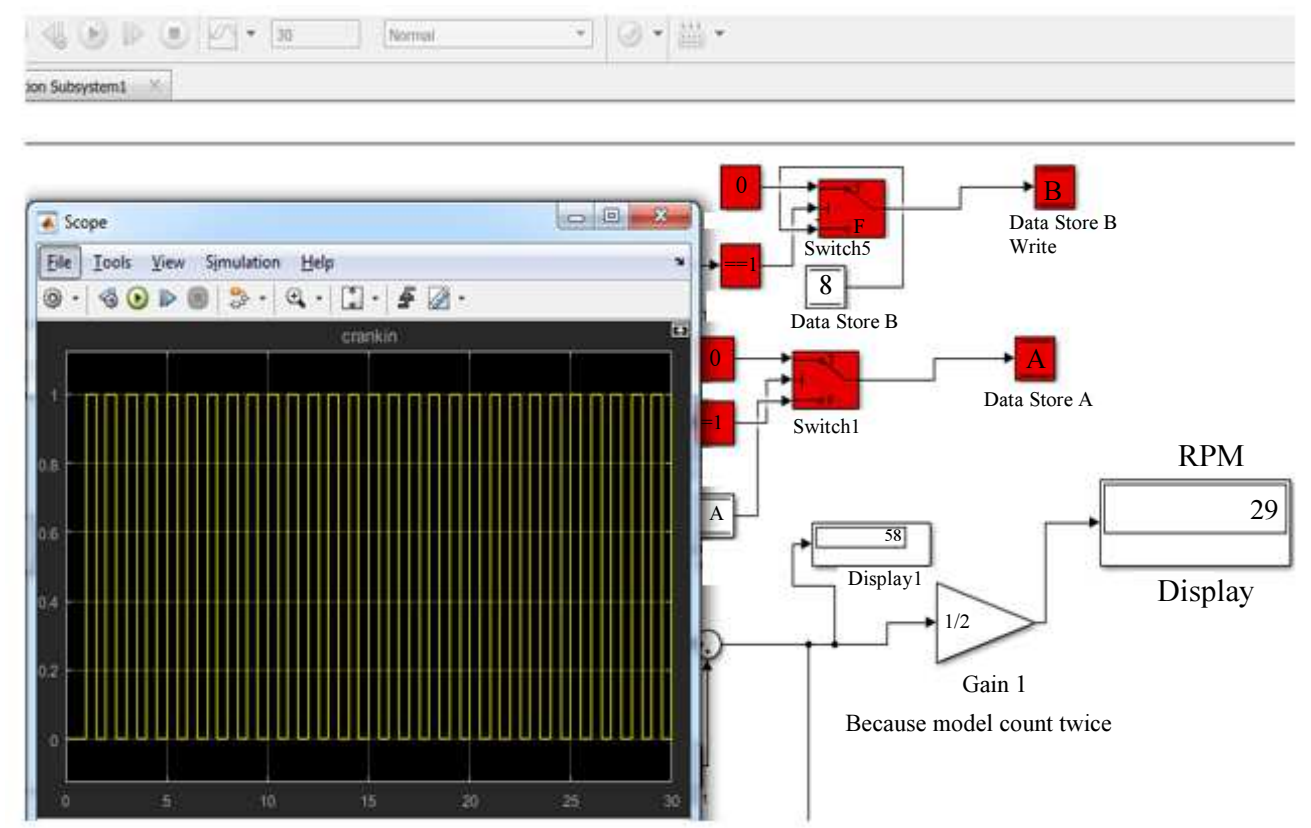

Fig. 16: Crank model testing with Simulated crank sensor signal

When model running, at the beginning the data store block $\mathrm{F}$ initial value is 0 , once high signal detected, the block will be increased by 1 so it is value will be 1 then the counter will store the counting value in the $\mathrm{C}$ data 
store block, once another detection of high the data store $\mathrm{F}$ will be increased by one to be 2 , so the $\mathrm{C}$ block value will be the same previous value and the Block $F$ will be reset to be zero value, after another detection will be increased by one to be 1 .

At the end when value of $F$ block reach 0 the value of $\mathrm{C}$ will be added to $\mathrm{X}$ output block

The next tooth subsystem:

It is enabled subsystem contain counter which start counting when enable block receiving 1 from the main input signal, the result of this counter will be input to switch block and will be added to the $\mathrm{D}$ data store in case the value of data store $J$ is 1 , if not equal 1 it will keep the same previous value of data store $\mathrm{D}$ as it is.

When model running at the beginning the data store block $\mathrm{J}$ initial value is 4 and once detection of high signal the block value will be decreased by one to be 3 , the counter will not store the counting value and the value of $\mathrm{D}$ data store will be the same which initially zero and once another detection of the block by other high signal the data store $\mathrm{J}$ will be decreased by one to be 2 so the $D$ block value will be the same previous value and after another detection will be decreased by one to be 1 , the counter value will be stored in $\mathrm{D}$ data store block, another high detection will decrease the $\mathbf{J}$ value by 1 to be 0 , which will reset the J block value to be 4 as initial value.

At the end when value of J block reach 4 the value of $\mathrm{D}$ will be added to $\mathrm{Y}$ output block then will compare the value of $\mathrm{X}$ with the Value of $\mathrm{Y}$ as follows:

1. 1-If same counting value, this means that the pulse width is the same which will give 0

2. 2-if different values this means that the pulse width is different and this is the marked wider tooth and will give 1 value, Fig. 17 shows testing the model with a simulated signal which has a repeated pulse with the same width and one different pulse with a wider width, when detecting the wider pulse and compared with the next the comparing results gives 1
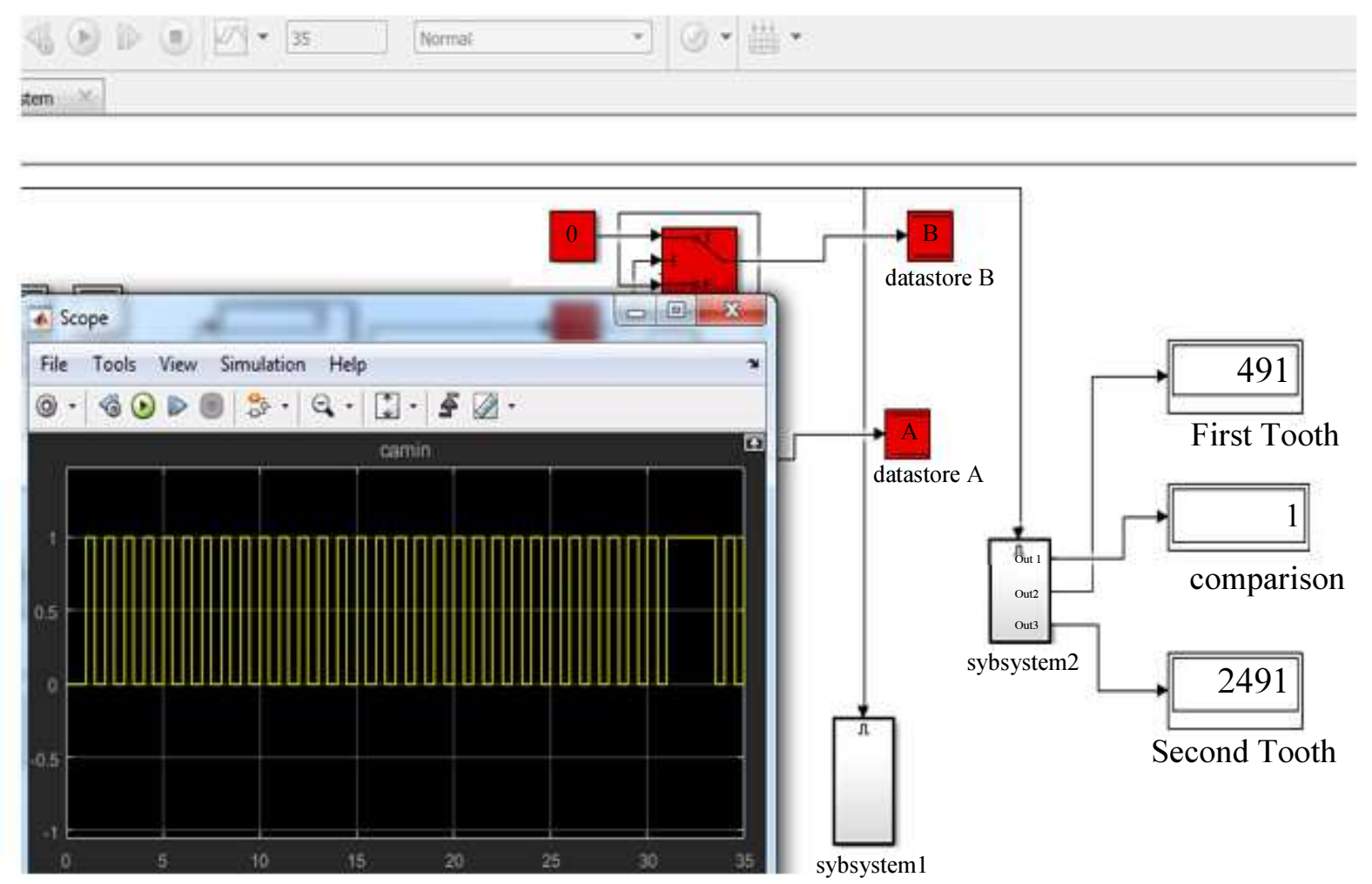

Fig. 17: Crank model tested with Simulated crank sensor signal

\section{Crank Sensor Model Injection Time}

The crank model for the mechatronics system will start injection before TDC by 9 degrees and since the crank sensor reluctor wheel installed to consider the piston will be before TDC by 12 degrees when detecting the marked tooth, so sholud implement a model to count 3 degrees after detecting the marked tooth which is difficult and 
will gives inaccurate results since the each pulse equal 6 degrees so the best solution is reinstall the reluctor wheel with 9 degree BTDC, so once the sensor detect the wider tooth this mean the piston 1 will inject and a fter detecting the wider tooth by 180 degree or 30 pulse the next cylinde will inject.

\section{Cam Senor Model Injection Order}

The cam model injection order 1342 .

The cam sensor reluctor wheel has four tooths, after detecting the marked tooth will inject cylinder 1 and when detecting the next pulse will inject cylinder 3 , next will be cylinder 4 then cylinder 2 .

\section{Models Generated C Code}

Using embedded coder toolbox, $\mathrm{C}$ code will be generated and manually integrated with the ECU input and output pins.

Part of crank sensor model generated $\mathrm{C}$ code:

* Model version: 1.26

crank_final_working_raspi_code_generation.c

* Code generated for Simulink model 'crank_final_working_raspi_code_generation'

* Simulink Coder version: 8.12 (R2017a)

* Target selection: ert.tlc

\#include

"crank_final_working_raspi_code_generation.h"

\#include

"crank_final_working_raspi_code_generation_private.h" \#include $<$ wiringPi.h>

/* Exported block signals */

int crankout; /*

/* Block states (auto storage) */

DW_crank_final_working_raspi_T

crank_final_working_raspi_co_ $\overline{\mathrm{DW}}$;

/* Real-time model */

- RT_MODEL_crank_final_working_T crank_final_working_raspi_co_M_;

RT_MODEL_crank_final_working_ ${ }^{-}{ }^{-}$*const crank_final_working_raspi_co_M =

\&crank_final_working_raspi_co_M_;

$/ *$ Model step function for TID $0 * /$

void

crank_final_working_raspi_code_generation_step0(void)

/* Sample time: [0.001s, 0.0s] */

\{

$$
\begin{aligned}
& \text { while } \\
& \text { \{ }
\end{aligned}
$$

wiringPisetup(); pinMode(23,INPUT);
crankin-digitalRead(23);

printf("crankout=\%d\n",crankout); int32_T rtb_Switch4;

real_T rtb_Sum1;

uint16 T rtb FixPtSum1;

uint16_T rtb_FixPtSwitch;

data storea $=\mathrm{A}$;

datastoreb $=\mathrm{B}$;

rtb_Switch $4=((\mathrm{A} !=0.0) \& \&(\mathrm{~B}==2.0))$;

rtb_Sum1 $=($ real_T)rtb_Switch4 +

crank_final_working_raspi_co_DW.Memory1_Previous Input;

\section{Speed Pedal Model}

This model used for determining the driver's wish so it works as input for the driver wish map to calculate the fuel injection quantity.

The model consisting of one lookup table contains potentiometer calibration data (Table 1).

\section{Torque Model}

In diesel engine the mass of air is constant but the mass flow rate is variable at variable speed, so at constant speed, the only variable in air to fuel ratio is the mass of fuel which will control the engine load by increasing or decreasing the fuel quantity.

This model (Fig. 18) is used for calculating the engine required fuel injected quantity trough two lookup tables:

The first lookup table is driver wish map which used for calculating the fuel injection quantity according to two inputs RPM and Pedal sensor value and will be created using the following equations (Heywood, 1988):

$P=\frac{\eta_{f} \eta_{v} N V_{d} Q_{H V} \rho_{a}(F / A)}{2}$

$T=\frac{\eta_{f} \eta_{v} V_{d} Q_{H V} \rho_{a}(F / A)}{4 \pi}$

Where:

$\mathrm{P} \quad=$ The power $(\mathrm{KW})$

$\mathrm{T} \quad=$ The Torque (N.M)

$\eta_{f} \quad=$ Fuel conversion efficiency

$\eta_{v}=$ Volumetric efficiency

$F / A=$ Fuel to air ratio

$Q_{H V}=$ Heating value of a fuel $(\mathrm{Mj} / \mathrm{kg} . \mathrm{k})$

$\rho_{a}=$ Inlet air density $\left(\mathrm{kg} / \mathrm{cm}^{3}\right)$

$V_{d} \quad=$ Cylinder volume $\left(\mathrm{cm}^{3}\right)$ 


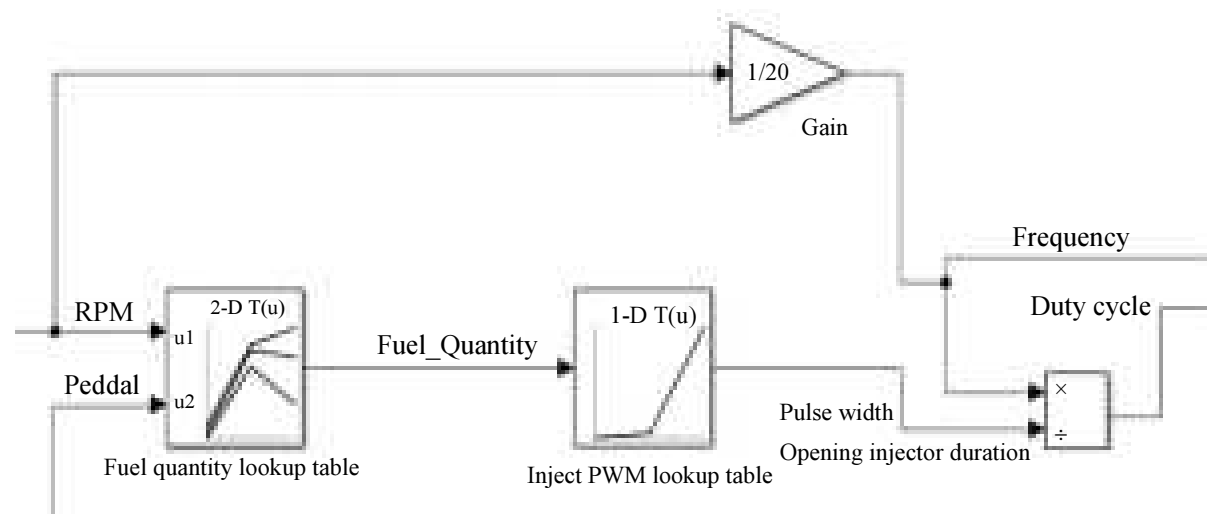

Fig. 18: Torque model

Table 1: Potentiometer calibration data

\begin{tabular}{ll}
\hline Incremental point & Volt \\
\hline 10 & 4.989 \\
9 & 4.713 \\
8 & 4.174 \\
7 & 3.705 \\
6 & 3.153 \\
5 & 2.650 \\
4 & 1.995 \\
3 & 1.355 \\
2 & 0.783 \\
1 & 0.403 \\
0 & 0.014 \\
\hline
\end{tabular}

Table 2: Practical fuel injection volume for $4 \mathrm{HF} 1$ zexel pump and zexel injector at different rpm

\begin{tabular}{lll}
\hline RPM & Period $(\mathrm{sec})$ & volume \\
\hline 520 & $116 \mathrm{sec}$ & $10 \mathrm{ml}$ \\
1380 & $52 \mathrm{sec}$ & $13 \mathrm{ml}$ \\
\hline
\end{tabular}

From Table 2 we can calculate practically the injector injection quantity at $520 \mathrm{rpm}$ and $1380 \mathrm{rpm}$ at no load in $\mathrm{mg}$ /stroke:

At $520 \mathrm{rpm}$ with no load and $116 \mathrm{sec}$, the injection quantity for one injector is $10 \mathrm{ml}$

Diesel fuel density $=840 \mathrm{~kg} / \mathrm{m}^{3}$

Convert the $10 \mathrm{ml}$ to $\mathrm{mg}=10 \times 840=8400 \mathrm{mg}$

the fuel injected per second for one injector $=8400 / 116$

$=72.413 \mathrm{mg} / \mathrm{sec}$ and to convert it to $\mathrm{mg} /$ stroke, number of injector strokes in one sec must be calculated as follows: engine rotations per $\sec =520 / 60=8.6$, since the enigne is four stroke engine so each injector will stroke once every four strokes which every two crank rotation, so for 8.6 rotations per sec the injector will stroke 8.6/2 $=4.3$ strokes, it mean the injector will inject 4.33 times, so the injection quantity for one injector at $520 \mathrm{rpm}=72.4 / 4.3$ $=16.72 \mathrm{mg} /$ stroke

At $1380 \mathrm{rpm}$ with no load and $52 \mathrm{sec}$ the fuel injection for one injector is $13 \mathrm{ml}$, convert $\mathrm{ml}$ to $\mathrm{mg} 13 \mathrm{ml}=13 \times$ $840=10920 \mathrm{mg}$

The fuel injected per second $10920 / 52=210 \mathrm{mg} / \mathrm{sec}$
Engine rotaions per $\mathrm{sec}=1380 / 60=23$

So for 23 rotations per sec the injector will stroke $23 / 2=$ 11.5 strokes then the injection quantity at $1380 \mathrm{rpm}=$ $210 / 11.5=18.26 \mathrm{mg} /$ stroke.

Calculation of other wish driver map points:

For Isuzu diesel engine, Volumetric efficiency is 0.8 , Fuel conversion efficiency assumed 0.3 , Heating value $=$ $44800000 \mathrm{j} / \mathrm{kg} . \mathrm{k}$, Cylinders volume $=4334 \mathrm{cc}=0.004334$ $\mathrm{m} 3$ and from engine performance curves at 1380rpm, power $=40.617 \mathrm{KW}$ and torque $=280.5 \mathrm{NM}$

Calculation for fuel injection quantity at $1380 \mathrm{rpm}$ with $80 \%$ peddal pressed

$280.5=0.3 \times 0.8 \times 448000 \times 0.004334 \times(\mathrm{f} / \mathrm{a}) / 12.56$

$\mathrm{F} / \mathrm{A}=0.0756$

each cylinder volume $=4334 / 4=1038 \mathrm{~cm}^{3}=1038 \mathrm{mg}$ and in $\mathrm{mg} /$ stroke $=1038 \mathrm{mg} /$ stroke

$\mathrm{F} / \mathrm{A})=0.0756=$ Mfuel/Mair

Mfuel $=1038 \times 0.0756=78.47 \mathrm{mg} /$ stroke.

Since $1380 \mathrm{rpm}$ engine speed cannot achieved by pressing on the peddal less than 20 to $80 \%$, So at 1380 rpm the calculations will be only for $20304050607080 \%$ From practical test at $1380 \mathrm{rpm}$ with $20 \%$ peddal pressed with no load: $\mathrm{F} / \mathrm{A}=18.26 / 1038=0.01759$, so the torque $\mathrm{T}=0.3 \times 0.8 \times 44800000 \times 0.004334 \times 0.01759 / 12.56=$ 65.26 N.M

For the other points (Table 3 ), Torque step $=280.5-65.26$ $=215.24 \mathrm{NM}, 215.24 / 6=35.87$

At $30 \%$ peddal and at $1380 \mathrm{rpm}$ the power $=14.62 \mathrm{KW}$ and torque $=101.13 \mathrm{NM}$ so for fuel quantity: $101.13=$ $0.3 \times 0.8 \times 44800000 \times 0.004334 \times(\mathrm{F} / \mathrm{A}) / 12.56$

Mfuel $=0.027 \times 1038=28.31 \mathrm{mg} /$ stroke

At $1380 \mathrm{rpm}$ and with $40 \%$ peddal pressed, the torque is $137, \mathrm{~F} / \mathrm{A}=137 / 3710.124=0.036$

Mfuel $=036 \times 1038=38.32 \mathrm{mg} /$ stroke and same calculation for other points (Table 4).

Second look up table is to convert the injection quantity to pulse width (Table 5). 
Mostafa Abdulrahman Kortam et al. / Journal of Mechatronics and Robotics 2018, Volume 2: 60.71 10.3844/jmrsp.2018.60.71

Table 3: Power and torque at $1380 \mathrm{rpm}$ and different pedal percentage

\begin{tabular}{|c|c|c|}
\hline Pedal \%@1380 & Power@1380 KW & Torque@1380 NM \\
\hline 0 & ---------- & 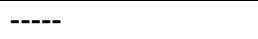 \\
\hline 10 & --------------- & ------- \\
\hline 20 & 9.420 & 65.260 \\
\hline 30 & 14.62 & 101.13 \\
\hline 40 & 19.80 & 137.00 \\
\hline 50 & 24.98 & 172.87 \\
\hline 60 & 30.17 & 208.74 \\
\hline 70 & 35.35 & 244.61 \\
\hline 80 & 40.54 & 280.50 \\
\hline
\end{tabular}

Table 4: Driver wish MAP

\begin{tabular}{|c|c|c|c|c|c|c|c|c|c|}
\hline Pedal & $0 \%$ & 10 & 20 & 30 & 40 & 50 & 60 & 70 & 80 \\
\hline \multicolumn{10}{|l|}{ rpm } \\
\hline 200 & 91.87 & -------- & -------- & ---------- & -------- & ---------- & --------- & ---------- & -------. \\
\hline 550 & 16.72 & -------- & -------- & ---------- & ---------- & ---------- & --------- & ---------- & -------. \\
\hline 965 & ---------- & 17.49 & 23.17 & 28.85 & 34.63 & 40.21 & 45.89 & 52.42 & 57.26 \\
\hline 1380 & ---------- & -------- & 18.26 & 28.31 & 38.32 & 48.36 & 58.40 & 68.4 & 78.47 \\
\hline 1795 & ---------- & -------- & -------- & 18.68 & 30.88 & 43.09 & 55.29 & 67.41 & 78.88 \\
\hline 2210 & ---------- & -------- & -------- & ---------- & 20.75 & 35.11 & 48.78 & 63.83 & 78.19 \\
\hline
\end{tabular}

Table 5: Common rail injectror testing results

\begin{tabular}{ll}
\hline Injection quantity $(\mathrm{mg})$ & Injector pulse width (msec) \\
\hline 10 & 0.2 \\
35 & 0.7 \\
60 & 1.2 \\
80 & 1.6 \\
105 & 2.1 \\
\hline
\end{tabular}

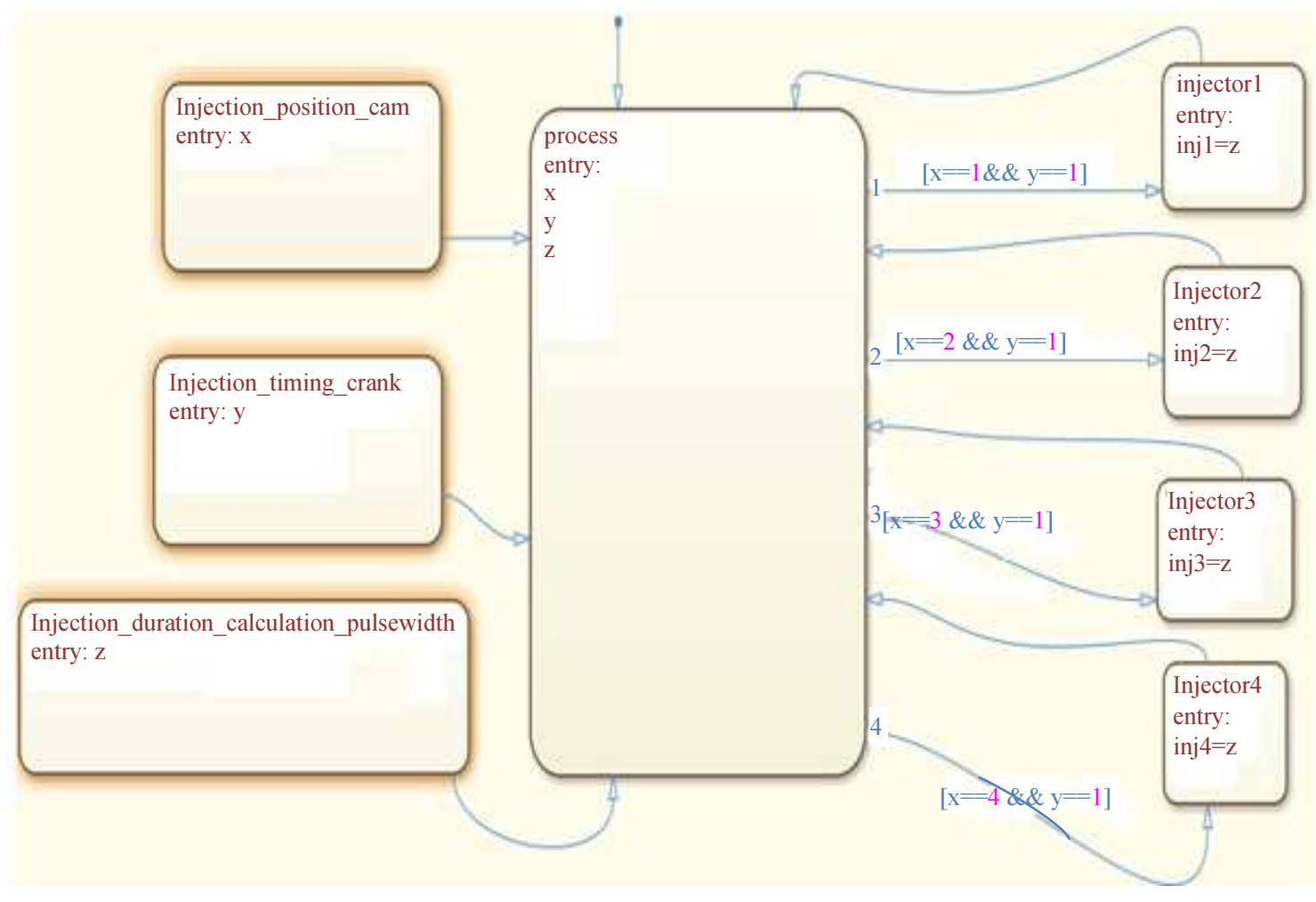

Fig. 19: Injectors stateflow chart 


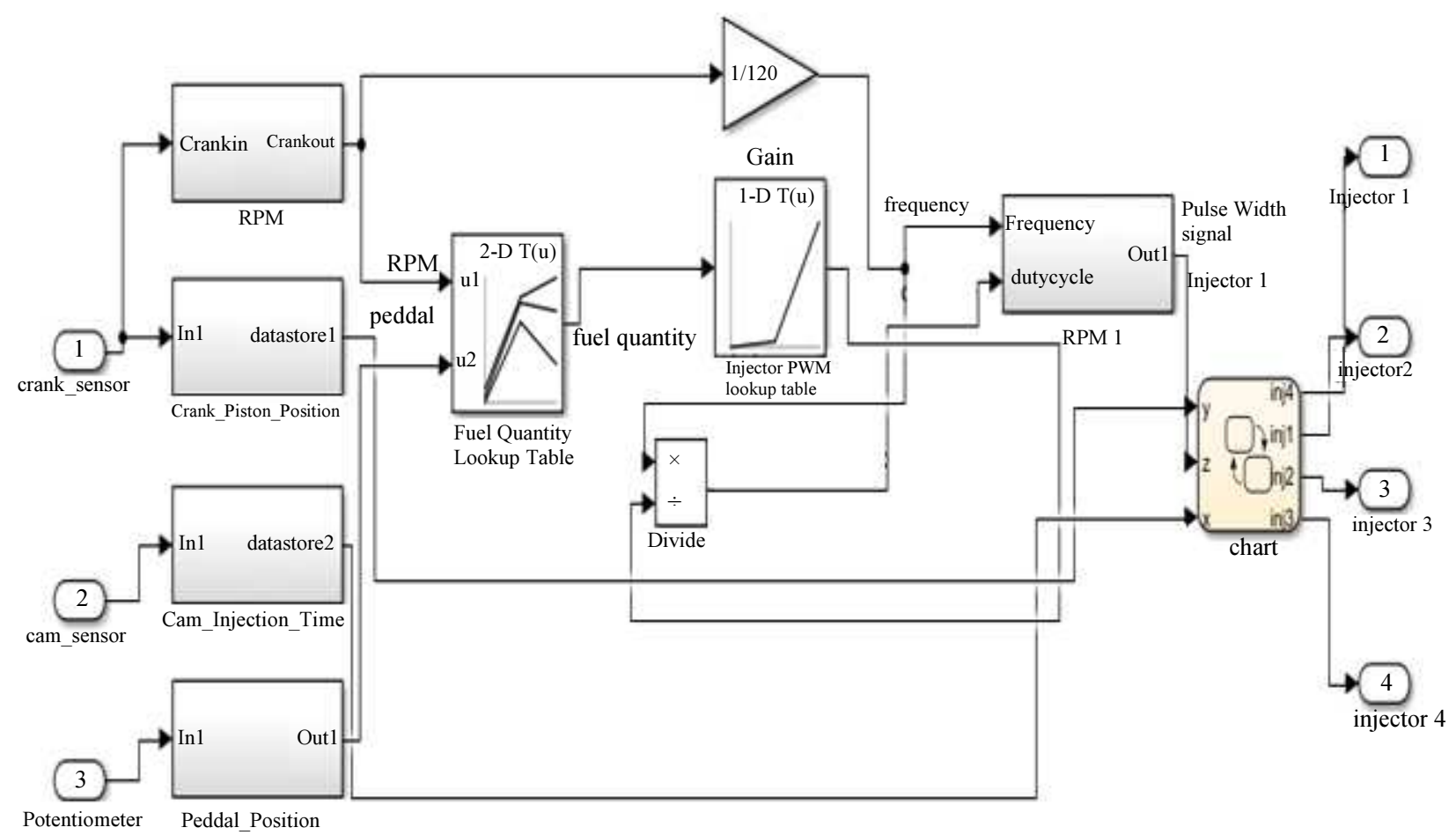

Fig. 20: Final simulink model

\section{Injectors Model}

This model (Fig. 19) for switching the 4 injectors with specific injection order and specific pulse width modulation signal.

The model contains:

1. PWM subsystem block which generates variable frequency variable duty cycle pulse width modulation signal according to the input data of duty cycle and engine frequency

2. Flowstate chart: The Stateflow chart used for specify the injector fuel injection order and injection time according to it is inputs which are the cam sensor signal, the crank sensor signal and the PWM signal(fuel injection quantity)

\section{Final Model}

This model (Fig. 20) is the final model which collecting all the previous models.

\section{Ecu C Code}

The Generated C Code from every model will integrate together manually then will integrate with the microcontroller layer which define all the controller hardware input and out pins, these pins will integrate with the input and output of the application layer.

At the end, this $\mathrm{C}$ code will compile and uploaded to the controller for starting the engine.

\section{Conclusion}

The engine started but not efficiently since there is a hunting and when trying to increase the rpm, the engine shut off, from this problem we can specify the important electronics fuel injection parameters which have the highest effect on the engine performance since this problem causes be as follows:1-At engine speed 420 rpm, the engine must inject at least three times per second and it is clear from the Fig. 21 oscilloscope reading that there is a lag in the injection pulses, this may be caused be the following:

- Lag in the processor speed since the raspberry pi is initially loaded with the Linux operating system.

- Transistor quality, which is not fast as required

- Transformer quality which causes a lag in the converting volt

- Wiring and connectors quality may cause lags in the system also, wiring length since when the wires have been shorted the engine starting improved

- Due to the size of the tooths, the tooths material and the way of installing, the cam sensor tooths signal have a problem

- From the piezoelectric injector testing results and the engine software, injector injection timig is too small since the working range is .2 to 2.6 miilsecond (600) microseconds which need a very efficient system to work with as CAN network 


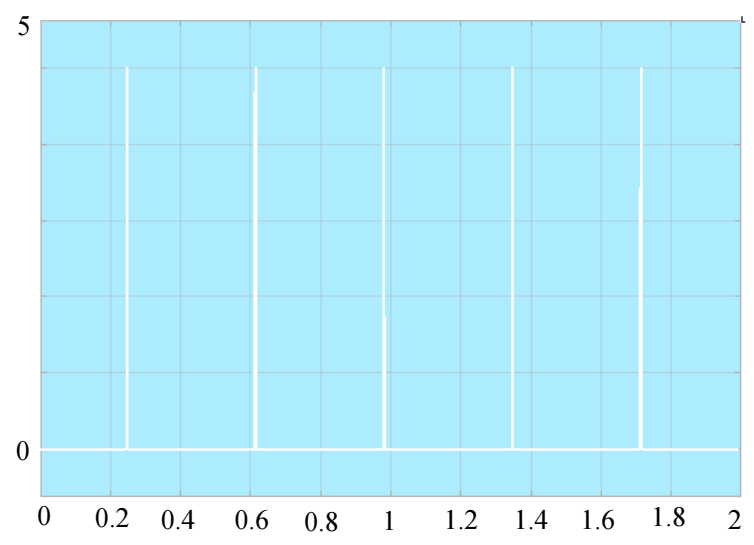

Fig. 21: The oscilloscope reading for injectors signal at $420 \mathrm{rpm}$

- Any lag in the processor speed will causes increase or decrease in the response of the injector opening and closing which will cause wrong injection quantity.

- The high-pressure fuel injection system increase the fuel pressure and speed which may be causes spreading the fuel into waves which hitting the cylinder walls and causes reflections and interferences which makes incomplete combustion.

- The injection quantity values in driver wish map (torque model/injection quantity lookup table) may be inaccurate and also the injector pulse width in the second lookup table may be not accurate hence the injector may inject more or less fuel than the required.

- The software may be need improvement to increase the speed of processing

- The injection timing for the mechanical system before the TDC by 12 degrees but for the mechatronics system this not starting the engine and started at 9 degrees before TDC, so with variable speed this value should be variable.

\section{Acknowledgement}

I would like to thank my thesis advisors Prof. Farid Abdulaziz Tolba, Faculty of Engineering, Mechatronics Engineering Department, Ain shams University, Cairo, Egypt and Dr.Adham Mohamed Abdelkader Hassen, Faculty of Engineering, Automotive Engineering Department, Ain shams University, Cairo, Egypt. Whenever I ran into a trouble spot or had a question about my research or writing. They consistently allowed this paper to be my own work, but steered me in the right the direction whenever they thought I needed it.

\section{Author's Contributions}

Mostafa Abdulrahman Kortam: Responsible on practical work, developing the ECU software and writing the paper.

Farid Abdulaziz Tolba: Supervised the project.

Adham Mohamed Abdelkader Hassen: Had the initial project idea and oversaw the research progress and contributed to the experimental design and engine control system. He also contributed in writing this paper.

\section{References}

AUTOSAR, 2017. Layered software architecture part of realease 4.3.1.

Bonnick, A.W.M., 2001. Automotive Computer Controlled Systems: Diagnostic Tools and Techniques. 1st Edn., Butterworth-Heinemann, Inglaterra, ISBN-10: 0750650893, pp: 252.

Heywood, J.B., 1988. Internal Combustion Engine Fundamentals. 1st Edn., McGraw-Hill, New York, ISBN-10: 0071004998, pp: 930.

Hoag, K. and B. Dondlinger, 2006. Vehicular Engine Design. 1st Edn.

Schäuffele, J. and T. Zurawka, 2005. Automotive Software Engineering: Principles, Processes, Methods and Tools. 1st Edn., SAE International, Warrendale, PA, ISBN-10: 0768014905, pp: 385.

Zurawski, R., 2009. Industrial Information Technology Series. In: Automotive Embedded Systems Handbook, Navet N. and F. Simonot-Lion (Eds.), CRC Press, ISBN-10: 0849380278. 